\title{
MEMORANDUM
}

No 32/2002

\section{A General Approach to Welfare Measurement through National Income Accounting}

\author{
By \\ Geir B. Asheim and Wolfgang Buchholz
}

\section{Department of Economics University of Oslo}


This series is published by the

University of Oslo Department of Economics

P. O.Box 1095 Blindern

N-0317 OSLO Norway

Telephone: +4722855127

Fax: $\quad+4722855035$

Internet: http://www.oekonomi.uio.no/

e-mail: $\quad \underline{\text { econdep } @ \text { econ.uio.no }}$
In co-operation with

The Frisch Centre for Economic Research

Gaustadalleén 21

N-0371 OSLO Norway

Telephone: $\quad+4722958820$

Fax: $\quad+4722958825$

Internet: http://www.frisch.uio.no/

e-mail: $\quad$ frisch@,frisch.uio.no

List of the last 10 Memoranda:

\begin{tabular}{|ll|l|}
\hline No 31 & $\begin{array}{l}\text { Geir B. Asheim } \\
\text { Green national accounting for welfare and sustainability: } \\
\text { A taxonomy of assumptions and results. 22 pp. }\end{array}$ \\
\hline No 30 & $\begin{array}{l}\text { Tor Jakob Klette and Arvid Raknerud } \\
\text { How and why do firms differ?. 40 pp. }\end{array}$ \\
\hline No 29 & $\begin{array}{l}\text { Halvor Mehlum, Kalle Moene and Ragnar Torvik } \\
\text { Institutions and the resource curse. 26 pp. }\end{array}$ \\
\hline No 28 & $\begin{array}{l}\text { Jon Strand } \\
\text { Public-good valuation and intrafamily allocation. } 37 \text { pp. }\end{array}$ \\
\hline No 27 & $\begin{array}{l}\text { Gabriela Mundaca } \\
\text { Optimal bailout during currency and financial crises: A sequential game } \\
\text { analysis. 41 pp. }\end{array}$ \\
\hline No 26 & $\begin{array}{l}\text { Halvor Mehlum } \\
\text { At Last! An Explicit Solution for the Ramsey Saddle Path. 6 pp. }\end{array}$ \\
\hline No 25 & $\begin{array}{l}\text { Steinar Holden and John C. Driscoll } \\
\text { Coordination, Fair Treatment and Inflation Persistence. 37 pp. }\end{array}$ \\
\hline No 24 & $\begin{array}{l}\text { Atle Seierstad } \\
\text { Maximum principle for stochastic control in continuous time with hard } \\
\text { end constraints. }\end{array}$ \\
\hline No 23 & $\begin{array}{l}\text { Hilde C. Bjørnland and Håvard Hungnes } \\
\text { Fundamental determinants of the long run real exchange rate: The case } \\
\text { of Norway. 40 pp. }\end{array}$ \\
\hline No 22 & $\begin{array}{l}\text { Atle Seierstad } \\
\text { Conditions implying the vanishing of the Hamiltonian at the infinite } \\
\text { horizon in optimal control problems. 3 pp. }\end{array}$ \\
\hline
\end{tabular}

A complete list of this memo-series is available in a PDF® format at: http://www.oekonomi.uio.no/memo/ 


\title{
A General Approach to Welfare Measurement through National Income Accounting*
}

\author{
Geir B. Asheim ${ }^{\dagger}$ and Wolfgang Buchholz ${ }^{\ddagger}$
}

September 26, 2002

\begin{abstract}
We develop a framework for analyzing national income accounting using a revealed welfare approach that is sufficiently general to cover, e.g., both the standard discounted utilitarian and maximin criteria as special cases. We show that the basic welfare properties of comprehensive national income accounting, which were previously ascribed only to the discounted utilitarian case, in fact extend to this more general framework. In particular, it holds under a wide range of circumstances that real NNP growth (or equivalently, a positive value of net investments) indicates welfare improvement. We illustrate the applicability of our approach by considering resource allocation mechanisms in the Dasgupta-Heal-Solow model of capital accumulation and resource depletion.
\end{abstract}

Journal of Economic Literature Classification Nos.: C43, D6, O47, Q01.

Keywords: National income accounting, dynamic welfare.

*We have benefited from discussions with Kenneth Arrow and Martin Weitzman. We also thank Lawrence Goulder, Peter Hammond, Geoffrey Heal, and David Miller for helpful comments. An earlier version has been circulated under the title "Progress, sustainability, and comprehensive national accounting". Much of this work was done while Asheim was visiting the research initiative on the Environment, the Economy and Sustainable Welfare at Stanford University, which hospitality is appreciated. We gratefully acknowledge financial support from the Hewlett Foundation (Asheim), CESifo Munich (Asheim), and the Research Council of Norway (Ruhrgas grant, both authors).

${ }^{\dagger}$ Department of Economics, University of Oslo, P.O. Box 1095 Blindern, N-0317 Oslo, Norway. Tel: +4722855498 Fax: +4722855035 Email: g.b.asheim@econ.uio.no

${ }^{\ddagger}$ Department of Economics, University of Regensburg, D-93040 Regensburg, Germany. Tel: +49 9419432711 Fax: +499419433176 Email: wolfgang.buchholz@wiwi.uni-regensburg.de 


\section{Introduction}

Net national product (NNP) represents the maximized value of the flow of goods and services that are produced by the productive assets of a society. If NNP increases, then society's capacity to produce has increased, and - one might think-society is better off. Although such an interpretation is often made in public debate, the assertion has been subject to controversy in the economic literature. While Samuelson (1961, p. 51) writes that "[o] ur rigorous search for a meaningful welfare concept has led to a rejection of all current income concepts ...", Weitzman (1976), in his seminal contribution, shows that greater NNP indicates higher welfare if

(a) dynamic welfare equals the sum of utilities discounted at a constant rate, and

(b) current utility equals the market value of goods and services consumed.

Weitzman's result is truly remarkable - as it means that changes in the stock of forward looking welfare can be picked up by changes in the flow of the value of current production-but, unfortunately, very strong assumptions are invoked. Recently, Asheim and Weitzman (2001) have established that assumption (b) can be relaxed when concerned with whether welfare is increasing locally in time: real NNP growth corresponds to welfare improvement even when current utility does not equal the market value of current consumption, as long as NNP is deflated by a Divisia consumption price index. It is the purpose of the present paper to show how also Weitzman's assumption (a) can be relaxed and a "snapshot" of the change in society's current performance still indicates change in dynamic welfare.

Why relax the assumption of discounted utilitarianism? First of all, such an assumption restricts the use of NNP comparisons for indicating welfare changes to situations where it can readily be determined that society maximizes the sum of utilities discounted at a constant rate. Moreover, there is a contradiction between having welfare correspond to discounted utilitarianism, on the one hand, and being concerned with welfare improvement, on the other hand, since increasing welfare over time does not have independent interest when society implements a path that maximizes the sum of discounted utilities. E.g., in the Dasgupta-Heal-Solow model (Dasgupta and Heal, 1974; Solow, 1974) of capital accumulation and resource depletion, eventually society's welfare is optimally decreasing along the discounted utilitarian path.

There are reasons to believe that real-world societies care about whether welfare is improving, both in terms of what proponents of economic growth may refer to as 
'progress' and in terms of what environmentalists call 'sustainability'. Two (perhaps hypothetical, but still relevant) explicit examples may serve as illustrations:

- Would we wish to follow a discounted utilitarian path if along this path people become worse off, even though sustained progress is feasible?

- And would we wish to follow a discounted utilitarian path if the emissions of greenhouse gases along this path in the next decades would seriously undermine the livelihood for most people $2-3$ centuries from now?

This raises the question: Is it possible to use the national accounting aggregate 'real NNP' as a tool for comparing welfare across time when we leave the framework of discounted utilitarianism, and instead consider social preferences and resource allocation mechanisms for which welfare improvement has independent interest? Within a wider class of situations it becomes more interesting to measure welfare changes, because such measurement might then yield information that is useful for the management of society's assets. If society, e.g., seeks to maximize the sum of discounted utilities within the subset of sustainable paths, does the observation that the growth rate of real NNP decreases towards zero indicate that unconstrained development is no longer sustainable?

Here we develop a framework for national accounting that is sufficiently general to incorporate such concerns. In particular, it is sufficiently general to include, in addition to discounted utilitarianism, also cases like

- maximin,

- undiscounted utilitarianism, and

- discounted utilitarianism with a sustainability constraint.

Thereby, we extend Weitzman's (1976) remarkable result — namely, that a "snapshot" of the change in society's current performance as measured by the change in real NNP indicates change in dynamic welfare, a result that was previously ascribed only to the discounted utilitarian case - to a far more general framework.

Our analysis will be based on the assumptions that society implements an efficient path that does not waste opportunity for welfare improvement. On this basis we will demonstrate how the underlying - but unspecified and unobservable - welfare judgements is revealed by current NNP, which in turn depends on the current prices and quantities that the implemented policies lead to in a perfect market economy. 
It is a prerequisite for the positive results - from Weitzman (1976) to the current paper - that the list of goods and services included in NNP is comprehensive. The national accounts are 'comprehensive' if all variable determinants of current productive capacity are included in the vector of capital stocks, and if all variable determinants of current well-being are included in the vector of consumption flows. E.g., compared to NNP as normally measured, one must "green" the national accounts by introducing natural resource depletion and environmental degradation into the national accounts by (i) including such depletion and degradation of natural capital as negative components to the vector of investment goods, and (ii) adding flows of environmental amenities to the vector of consumption goods.

These findings from national income accounting correspond to the result that the value of net investments has the following welfare significance under discounted utilitarianism: Welfare is increasing if and only if the value of net investments is positive. Thus, in an economy with natural capital, welfare is increasing if and only if the accumulation of manmade capital (including stocks of knowledge) in value more than compensates for natural resource depletion and environmental degradation. This is already proven by Weitzman (1976, eq. (14)) under the assumption of discounted utilitarianism, although the result is not emphasized by him. It has been reported in several contributions, including Hamilton and Clemens (1999), Pemberton and Ulph (2001), and, in a different setting, Dasgupta and Mäler (2000).

Here we first show that this result holds even outside the realm of discounted utilitarianism, before using the analysis of Asheim and Weitzman (2001) to establish that a positive value of net investments correspond to real NNP growth. Hence, it holds under quite general assumptions that welfare improvement can be indicated in two ways; either by increasing real NNP, or by the value of consumption falling short of NNP so that the value of net investments is positive.

We present the basic model in Sect. 2, before we in Sect. 3 take a look at national income accounting in the special cases of discounted utilitarianism and maximin. Then we turn in Sect. 4 to our general framework for revealed welfare analysis, and show in the following Sect. 5 how this framework means that real NNP growth can indicate welfare improvement in a general setting. Finally, we illustrate the applicability of our framework in Sect. 6 by considering progress and sustainability in the Dasgupta-Heal-Solow model, and conclude in Sect. 7. 


\section{The model}

Our analysis is performed within the technological environment used by Asheim and Weitzman (2001), who generalize Weitzman (1976) by allowing multiple consumption goods.

Let the vector $\mathbf{C}$ represent a $m$-dimensional fully-disaggregated consumption bundle, containing all variable determinants of current instantaneous well-being, including environmental amenities and other externalities. (Supplied labor corresponds to negative components.) Current consumption is presumed to be fully observable, along with its associated $m$-vector of efficiency prices.

Let $U$ be a given concave and non-decreasing utility function with continuous partial derivatives that assigns instantaneous utility $U(\mathbf{C})$ to any consumption vector C. The preferences over $\mathbf{C}$ at time $t$ are thus separable from the quantities consumed at other times, which is a standard assumption in growth theory. Since all nonconstant flows of consumption services are included in $\mathbf{C}$, the $U$-function allows comparisons across time. Thus, the society's instantaneous well-being is increased by moving from $\mathbf{C}^{\prime}$ to $\mathbf{C}^{\prime \prime}$ if and only if $U\left(\mathbf{C}^{\prime}\right)<U\left(\mathbf{C}^{\prime \prime}\right)$, which is again a standard assumption.

There are $n$ capital goods, including not only the usual kinds of man-made capital stocks, but also stocks of natural resources, environmental assets, human capital (like education and knowledge capital accumulated from R\&D-like activities), and other durable productive assets. The stock of capital of type $j$ at time $t$ is denoted $K_{j}(t)$, and its corresponding net investment flow is $I_{j}(t)=\dot{K}_{j}(t)$. The $n$-vector $\mathbf{K}=\left(K_{j}\right)$ denotes all capital stocks, while $\mathbf{I}=\left(I_{j}\right)$ stands for the corresponding $n$-vector of net investments. The net investment flow of a natural capital asset is negative if the overall extraction rate exceeds the replacement rate.

Assume that the coverage of capital goods is so comprehensive, and the national accounting system so complete, that all variable determinants of current productive capacity are included in the vector of capital stocks. Thus, all sources of development are captured by I, valued at efficiency prices, and included in national product. Formally, the $(m+n)$-dimensional set of attainable consumption-investment pairs is a function $S$ only of the available capital stocks $\mathbf{K}$, not of time. Hence, the consumption-investment pair $(\mathbf{C}, \mathbf{I})$ is attainable given $\mathbf{K}$ if and only if

$$
(\mathbf{C}, \mathbf{I}) \in S(\mathbf{K}) \text {. }
$$

Assume that, for all $\mathbf{K}, S(\mathbf{K})$ is a convex and smooth set. By the assumption of 
smoothness we abstract from the issue of non-negativity constraints.

The set of the attainable consumption-investment pairs, $S(\mathbf{K})$, given the current capital stocks, $\mathbf{K}$, constitutes the current productive capacity. In a perfect market economy, NNP corresponds to the maximized market value of current productive capacity. As time passes, NNP changes both because $\mathbf{K}$, and thus productive capacity $S(\mathbf{K})$, change due to a non-zero vector of net investments, and because the efficiency prices of the consumption and investment vectors change. The question posed in the introduction and analyzed in this paper is how an increased market value of the current productive capacity $S(\mathbf{K})$ can be interpreted as welfare improvement.

Since NNP is used for (a) consumption now and (b) accumulation of capital goods yielding increased future consumption, such an interpretation can be made only if welfare is dynamic: The welfare judgements must not only take into account the utility derived from current consumption, but must also reflect the utility possibilities that future consumption will give rise to. For this purpose, we assume that society's welfare judgements are described by complete and transitive social preferences on the set of utility paths. However, these underlying social preferences are assumed not to be directly observable by the national accountant.

What the national accountant can observe at any point in time is how the agents in society make decisions according to a resource allocation mechanism that assigns an attainable consumption-investment pair $(\mathbf{C}(\mathbf{K}), \mathbf{I}(\mathbf{K}))$ to any vector of capital stocks $\mathbf{K} .{ }^{1}$ We assume that the functions $\mathbf{C}$ and $\mathbf{I}$ are continuous everywhere and differentiable almost everywhere, and that there exists a unique solution $\left\{\mathbf{K}^{*}(t)\right\}$ to the differential equations $\dot{\mathbf{K}}^{*}(t)=\mathbf{I}\left(\mathbf{K}^{*}(t)\right)$ that satisfies the initial condition $\mathbf{K}^{*}(0)=\mathbf{K}^{0}$, where $\mathbf{K}^{0}$ is given. Hence, $\left\{\mathbf{K}^{*}(t)\right\}$ is the capital path that the resource allocation mechanism implements. Write $\mathbf{C}^{*}(t):=\mathbf{C}\left(\mathbf{K}^{*}(t)\right)$ and $\mathbf{I}^{*}(t):=\mathbf{I}\left(\mathbf{K}^{*}(t)\right)$.

Since the resource allocation mechanism in this manner implements a utility path $\left\{U\left(\mathbf{C}^{*}(t)\right)\right\}$ for any vector of initial capital stocks $\mathbf{K}^{0}$, the social preferences yield a complete and transitive binary relation on the set of capital vectors, under the presumption that paths are implemented by the resource allocation mechanism. Assume that, for given social preferences and resource allocation mechanism, there exists an ordinal welfare index, $W$, that represents this binary relation. The $W$ function signifies that society's dynamic welfare is increased by moving from $\mathbf{K}^{\prime}$ to $\mathbf{K}^{\prime \prime}$ if and only if $W\left(\mathbf{K}^{\prime}\right)<W\left(\mathbf{K}^{\prime \prime}\right)$. Since $W$ is ordinal, the welfare index is unique up to a monotone transformation.

\footnotetext{
${ }^{1}$ This is inspired by Dasgupta (2001, p. C20) and Dasgupta and Mäler (2000).
} 
Throughout the next sections we will invoke differentiability assumptions that, of course, will be satisfied in the specific examples we consider. We do so in order to present the basic results in a setting that focuses on the welfare interpretation of national accounting. In the case of $W$, we make two such assumptions: (i) We assume that $W$ is continuous everywhere and differentiable almost everywhere, and (ii) we assume that the implemented path of capital stocks, $\left\{\mathbf{K}^{*}(t)\right\}$, does not spend a positive measure of time at points in $\mathbf{K}$-space at which $W$ is not differentiable, except when absorbed at some capital vector $\mathbf{K}^{\infty}$, so that $\mathbf{I}^{*}(t)=\mathbf{I}\left(\mathbf{K}^{\infty}\right)=0$ and $\mathbf{K}^{*}(t)=\mathbf{K}^{\infty}$ from then on. Also, to retain focus, we refer to optimal control theory and the maximum principle throughout the next sections under standard assumptions, without explicitly stating what these assumption are.

After motivating issues in the next section by discussing the special cases of discounted utilitarianism and maximin, we raise in Sect. 4 the following general question: What kind of (invisible) guiding of the resource allocation mechanism by the (unobservable) social preferences implies that the underlying welfare concerns will be revealed through national income accounting?

\section{Discounted utilitarianism and maximin}

A main motivation for the analysis of the present paper is that it applies to a variety of methods for aggregating the interests of different generations in social evaluation. Discounted utilitarianism is the conventional example of social preferences in the intertemporal context. A prime example of an alternative welfare criterion is maximin - i.e., the ranking of paths according to the utility of the worst-off generationas proposed by Rawls (1971) and Solow (1974). As these are two important and often applied kinds of social preferences, we first seek to determine properties that hold for resource allocation mechanisms that implement discounted utilitarianism and maximin. This will in turn point to properties that will ensure welfare significance for national income accounting also in the case of maximin as well as a wider set of social preferences and resource allocation mechanisms.

It seems natural to identify the value of the welfare index, $W(\mathbf{K})$, with the utility level that if held constant is equally as good as the implemented utility path given $\mathbf{K}$ as the vector of initial stocks. This corresponds to a standard constructive technique for preference representation in consumer theory (see, e.g., Mas-Colell et al., 1995, pp. 47-8, and Varian, 1992, p. 97), and is inspired by Hicks (1946, ch. 14) 
and Weitzman (1976) in the present context. As shown below, $W(\mathbf{K})$ can be defined as such a stationary equivalent of future utility in the special cases of discounted utilitarianism and maximin.

Discounted utilitarianism. In the case of discounted utilitarianism, social preferences are represented by

$$
\int_{0}^{\infty} e^{-\rho t} U(\mathbf{C}(t)) d t
$$

where $\rho$ is a positive and constant utility discount rate. Assume that the resource allocation mechanism, for any vector of initial capital stocks $\mathbf{K}^{0}$, implements a path $\left\{\mathbf{C}^{*}(t), \mathbf{I}^{*}(t), \mathbf{K}^{*}(t)\right\}$ that maximizes (1) over all feasible consumption paths. By the maximum principle there exists a path $\{\boldsymbol{\Psi}(t)\}$ of investment prices in terms of utility such that $\left(\mathbf{C}^{*}(t), \mathbf{I}^{*}(t)\right)$ maximizes $U(\mathbf{C})+\mathbf{\Psi}(t) \mathbf{I}$ subject to $(\mathbf{C}, \mathbf{I}) \in S\left(\mathbf{K}^{*}(t)\right)$ at each $t$. Associate welfare $W\left(\mathbf{K}^{0}\right)$ with the utility level that if held constant is equally as good as the implemented path:

$$
W\left(\mathbf{K}^{0}\right)=\frac{\int_{0}^{\infty} e^{-\rho t} U\left(\mathbf{C}^{*}(t)\right) d t}{\int_{0}^{\infty} e^{-\rho t} d t}=\rho \int_{0}^{\infty} e^{-\rho t} U\left(\mathbf{C}^{*}(t)\right) d t .
$$

It is the main result of Weitzman (1976) that

$$
U\left(\mathbf{C}^{*}(0)\right)+\mathbf{\Psi}(0) \mathbf{I}^{*}(0)=\rho \int_{0}^{\infty} e^{-\rho t} U\left(\mathbf{C}^{*}(t)\right) d t
$$

Hence, $W\left(\mathbf{K}^{0}\right)=U\left(\mathbf{C}^{*}(0)\right)+\mathbf{\Psi}(0) \mathbf{I}^{*}(0)$ under discounted utilitarianism.

Since $\boldsymbol{\Psi}(0)$ is the vector of partial derivatives of $\int_{0}^{\infty} e^{-\rho t} U\left(\mathbf{C}^{*}(t)\right) d t$ w.r.t. the initial stocks, we obtain that the vector of partial derivatives of $W, \nabla W\left(\mathbf{K}^{0}\right)$, equals $\rho \boldsymbol{\Psi}(0)$. By the maximum principle it now follows that

$$
\left(\mathbf{C}^{*}(0), \mathbf{I}^{*}(0)\right) \text { maximizes } \rho U(\mathbf{C})+\nabla W\left(\mathbf{K}^{0}\right) \mathbf{I} \text { subject to }(\mathbf{C}, \mathbf{I}) \in S\left(\mathbf{K}^{0}\right),
$$

since $\rho U(\mathbf{C})+\nabla W\left(\mathbf{K}^{0}\right) \mathbf{I}=\rho \cdot(U(\mathbf{C})+\mathbf{\Psi}(0) \mathbf{I})$ and $\rho>0$.

Maximin. In the case of maximin, social preferences are represented by

$$
\inf _{t} U(\mathbf{C}(t)) \text {. }
$$

Assume that the resource allocation mechanism implements maximin and results in an efficient path with constant utility; formally, what Burmeister and Hammond (1977) and Dixit et al. (1980) call a regular maximin path. Then with $\mathbf{K}^{*}(0)=\mathbf{K}^{0}$ 
as the initial condition there exists a path of utility discount factors $\{\mu(t)\}$ such that it is as if the implemented path $\left\{\mathbf{C}^{*}(t), \mathbf{I}^{*}(t), \mathbf{K}^{*}(t)\right\}$ maximizes

$$
\int_{0}^{\infty} \mu(t) U(\mathbf{C}(t)) d t
$$

over all feasible consumption paths. Since $U\left(\mathbf{C}^{*}(t)\right)$ is constant, it follows that $\int_{0}^{\infty} \mu(t) d t$ is finite. This requirement is satisfied if the supporting utility discount rates, $-\dot{\mu}(t) / \mu(t)$, are positive and do not decrease too fast. Again, by the maximum principle there exists a path $\{\boldsymbol{\Psi}(t)\}$ of investment prices in terms of utility such that $\left(\mathbf{C}^{*}(t), \mathbf{I}^{*}(t)\right)$ maximizes $U(\mathbf{C})+\mathbf{\Psi}(t) \mathbf{I}$ subject to $(\mathbf{C}, \mathbf{I}) \in S\left(\mathbf{K}^{*}(t)\right)$ at each $t$.

Associate welfare $W\left(\mathbf{K}^{0}\right)$ also in this case with the utility level that if held constant is equally as good as the implemented path. It follows trivially that the constant utility level is a welfare index along a regular maximin path:

$$
W\left(\mathbf{K}^{0}\right)=U\left(\mathbf{C}^{*}(t)\right)=\frac{\int_{0}^{\infty} \mu(t) U\left(\mathbf{C}^{*}(t)\right) d t}{\int_{0}^{\infty} \mu(t) d t} .
$$

By the converse of Hartwick's rule (cf. Dixit et al., 1980; Hartwick, 1977; Withagen and Asheim, 1998), we have that $\mathbf{\Psi}(t) \mathbf{I}^{*}(t)=0$ at each $t$. Hence, $W\left(\mathbf{K}^{0}\right)=$ $U\left(\mathbf{C}^{*}(0)\right)+\mathbf{\Psi}(0) \mathbf{I}^{*}(0)$ even under maximin.

Since $\boldsymbol{\Psi}(0)$ is the vector of partial derivatives of

$$
\int_{0}^{\infty} \frac{\mu(t)}{\mu(0)} U\left(\mathbf{C}^{*}(t)\right) d t
$$

w.r.t. the initial stocks, we obtain by invoking the envelope theorem that

$$
\nabla W\left(\mathbf{K}^{0}\right)=\rho^{*} \mathbf{\Psi}(0) \quad \text { with } \quad \rho^{*}:=\frac{\mu(0)}{\int_{0}^{\infty} \mu(t) d t},
$$

where $\rho^{*}$ is the infinitely long-term supporting utility discount rate at time 0 , which equals the discounted average of the (instantaneous) utility discount rate $-\dot{\mu}(t) / \mu(t)$ from time 0 on. Note that $W$ is differentiable everywhere also in the case of maximin. By the maximum principle it follows that

$$
\left(\mathbf{C}^{*}(0), \mathbf{I}^{*}(0)\right) \text { maximizes } \rho^{*} U(\mathbf{C})+\nabla W\left(\mathbf{K}^{0}\right) \mathbf{I} \text { subject to }(\mathbf{C}, \mathbf{I}) \in S\left(\mathbf{K}^{0}\right),
$$

since $\rho^{*} U(\mathbf{C})+\nabla W\left(\mathbf{K}^{0}\right) \mathbf{I}=\rho^{*} \cdot(U(\mathbf{C})+\mathbf{\Psi}(0) \mathbf{I})$ and $\rho^{*}>0 .^{2}$

\footnotetext{
${ }^{2}$ We are actually offering a simple proof of the converse of Hartwick's rule through the observation that $\nabla W\left(\mathbf{K}^{*}(t)\right)$ is proportional to $\Psi^{*}(t)$ : Constant utility implies that $0=d W\left(\mathbf{K}^{*}(t)\right) / d t=$ $\nabla W\left(\mathbf{K}^{*}(t)\right) \mathbf{I}^{*}(t)$, which due to proportionality of $\nabla W\left(\mathbf{K}^{*}(t)\right)$ and $\Psi(t)$ yields $\Psi(t) \mathbf{I}^{*}(t)=0$. Cairns (2000) makes a similar observation.
} 
Thus, the cases of discounted utilitarianism and maximin allow us to make the following two observations:

1. By referring to $U\left(\mathbf{C}^{*}(0)\right)+\mathbf{\Psi}(0) \mathbf{I}^{*}(0)$ as net national product in terms of utility (or "utility NNP"), we get in both cases that utility NNP is a global representation of dynamic welfare, in the sense that welfare is greater if and only if utility NNP is greater.

2. By interpreting $\rho$ (resp. $\rho^{*}$ ) as a Lagrangian multiplier associated with the constraint that $U(\mathbf{C}) \geq U\left(\mathbf{C}^{*}(0)\right)$, we get in both cases that welfare improvement at time $0, \nabla W\left(\mathbf{K}^{0}\right) \mathbf{I}$, is maximized subject to (a) $(\mathbf{C}, \mathbf{I})$ being attainable, and (b) utility at time 0 being at least $U\left(\mathbf{C}^{*}(0)\right)$.

The analysis of this paper will show how property 2 can be used as the basis for revealed welfare analysis under a wider set of circumstances. Furthermore, it yields welfare significance to national accounting aggregates that are measurable in terms of market prices (within our idealized setting).

In contrast, we show that property 1 cannot be generalized; it does for example not apply to the case of undiscounted utilitarianism (cf. Sect. 6.1). In any case, utility NNP is not per se a measurable national accounting aggregate, unless utility is directly measurable by means of market prices.

We now turn to the general analysis.

\section{Resource allocation and welfare improvement}

Fix the underlying, but unobservable, social preferences used to rank utility paths, and consider a resource allocation mechanism. What assumptions on the resource allocation mechanism are both (i) strong enough for the underlying welfare concerns to be revealed through national accounting and (ii) weak enough to hold for a wide range of circumstances? In this section we answer this question by imposing on the resource allocation mechanism two assumptions that hold if the most preferred paths under discounted utilitarianism and maximin are implemented. However, as illustrated in Sect. 6, these assumptions yield results with much wider application.

The first of these assumptions is the following.

Assumption 1 (Implementation of an efficient path) Let $\left\{\mathbf{C}^{*}(t), \mathbf{I}^{*}(t), \mathbf{K}^{*}(t)\right\}$ be the path implemented by the resource allocation mechanism with $\mathbf{K}^{*}(0)=\mathbf{K}^{0}$ as 
initial condition. Then there exists a continuous path of positive supporting utility discount factors $\{\mu(t)\}$, with

$$
-\frac{\dot{\mu}(t)}{\mu(t)}>0
$$

at almost every $t$, such that it is as if $\left\{\mathbf{C}^{*}(t), \mathbf{I}^{*}(t), \mathbf{K}^{*}(t)\right\}$ maximizes

$$
\int_{0}^{\infty} \mu(t) U(\mathbf{C}(t)) d t
$$

over all feasible consumption paths with $\mathbf{K}^{*}(0)=\mathbf{K}^{0}$ as initial condition.

This assumption is clearly satisfied when discounted utilitarianism is implemented, and also for maximin when implementation of this criterion leads to a regular maximin path with a supporting path of positive utility discount rates (cf. Sect. 3). The maximization is as if since $\int_{0}^{\infty} \mu(t) U(\mathbf{C}(t)) d t$ is not necessarily the primitive objective of the society. As illustrated by the maximin case, the path of supporting utility discount factors $\{\mu(t)\}$ may simply characterize the implemented path without having by itself any welfare significance.

By the maximum principle there exists a continuous path $\{\boldsymbol{\Psi}(t)\}$ of investment prices in terms of utility such that, at each $t$,

$$
\left(\mathbf{C}^{*}(t), \mathbf{I}^{*}(t)\right) \text { maximizes } U(\mathbf{C})+\mathbf{\Psi}(t) \mathbf{I} \text { subject to }(\mathbf{C}, \mathbf{I}) \in S\left(\mathbf{K}^{*}(t)\right) .
$$

This yields the maximized current-value Hamiltonian:

$$
\begin{aligned}
H^{*}(t)=H\left(\mathbf{K}^{*}(t), \mathbf{\Psi}(t)\right): & =\max _{(\mathbf{C}, \mathbf{I}) \in S\left(\mathbf{K}^{*}(t)\right)} U(\mathbf{C})+\mathbf{\Psi}(t) \mathbf{I} \\
& =U\left(\mathbf{C}^{*}(t)\right)+\mathbf{\Psi}(t) \mathbf{I}^{*}(t) .
\end{aligned}
$$

Refer to $\mathbf{\Psi I}^{*}$ as the value of net investments. Furthermore, we have as co-state differential equations that

$$
\nabla_{\mathbf{K}} H\left(\mathbf{K}^{*}(t), \boldsymbol{\Psi}(t)\right)=-\frac{\dot{\mu}(t)}{\mu(t)} \mathbf{\Psi}(t)-\dot{\mathbf{\Psi}}(t)
$$

where $\nabla$ denotes a vector of partial derivatives, and where $-\dot{\mu}(t) / \mu(t)$ is the supporting instantaneous rate of utility discount at time $t$.

The following basic result - which is at the heart of the analyses of e.g. Weitzman (1976, cf. eq. (14)) and Dixit et al. (1980, cf. Theorem 1) — can now be established.

Lemma 1 Under Assumption 1, $U\left(\mathbf{C}^{*}(t)\right)+\mathbf{\Psi}(t) \mathbf{I}^{*}(t)$ is continuous and

$$
\nabla U\left(\mathbf{C}^{*}(t)\right) \dot{\mathbf{C}}^{*}(t)+d\left(\boldsymbol{\Psi}(t) \mathbf{I}^{*}(t)\right) / d t=-\frac{\dot{\mu}(t)}{\mu(t)} \mathbf{\Psi}(t) \mathbf{I}^{*}(t)
$$

holds at almost every $t$. 
Proof. $H^{*}=U\left(\mathbf{C}^{*}\right)+\mathbf{\Psi} \mathbf{I}^{*}$ is continuous since $\mathbf{K}^{*}$ and $\boldsymbol{\Psi}$ are continuous. By (3), (4), and the envelope theorem, it follows that

$$
\dot{H}^{*}=\nabla_{\mathbf{K}} H \mathbf{I}^{*}+\nabla_{\mathbf{\Psi}} H \dot{\mathbf{\Psi}}=\left(-\frac{\dot{\mu}}{\mu} \mathbf{\Psi}-\dot{\mathbf{\Psi}}\right) \mathbf{I}^{*}+\dot{\mathbf{\Psi}} \mathbf{I}^{*}=-\frac{\dot{\mu}}{\mu} \mathbf{\Psi} \mathbf{I}^{*}
$$

holds at almost every $t$. However, (3) also directly implies that

$$
\dot{H}^{*}=\nabla U\left(\mathbf{C}^{*}\right) \dot{\mathbf{C}}^{*}+d\left(\mathbf{\Psi} \mathbf{I}^{*}\right) / d t
$$

The second part of the lemma is obtained by combining (5) and (6).

This result says that change in utility NNP equals the supporting utility discount rate times the value of net investments.

An additional assumption is needed to ensure that the underlying welfare concerns can be revealed through national accounting. Assume, as in Sect. 2, that the binary relation over vectors of stocks for given resource allocation mechanism is represented by a welfare index, $W$, that is unique up to a monotone transformation. However, in contrast to the discussion in Sect. 3, $W(\mathbf{K})$ need not be associated with a stationary equivalent utility level.

Except for the technical assumptions made in Sect. 2, we do not make any assumptions on how $W(\mathbf{K})$ depends on $\mathbf{K}$. Rather, in addition to Assumption 1, we only impose that the resource allocation mechanism and the accompanying welfare index satisfy that welfare improvement is maximized subject to the current utility level being attainable. This is stated by the following assumption, where $\rho(\mathbf{K})$ is formally a Lagrangian multiplier on the lower bound for utility.

Assumption 2 (No waste of welfare improvement) For almost every $\mathbf{K}$, there exists $\rho(\mathbf{K})>0$ such that

$(\mathbf{C}(\mathbf{K}), \mathbf{I}(\mathbf{K}))$ maximizes $\rho(\mathbf{K}) U(\mathbf{C})+\nabla W(\mathbf{K}) \mathbf{I}$ subject to $(\mathbf{C}, \mathbf{I}) \in S(\mathbf{K})$.

By writing $W^{*}(t):=W\left(\mathbf{K}^{*}(t)\right)$ for the welfare level along the implemented path $\left\{\mathbf{C}^{*}(t), \mathbf{I}^{*}(t), \mathbf{K}^{*}(t)\right\}$, so that $\dot{W}^{*}(t)=\nabla W\left(\mathbf{K}^{*}(t)\right) \mathbf{I}^{*}(t)$, we see how this assumption entails that welfare improvement is maximized subject to $(\mathbf{C}, \mathbf{I})$ being attainable and utility at $t$ being at least $U\left(\mathbf{C}^{*}(t)\right)$. We have observed in Sect. 3 that Assumption 2 is satisfied when discounted utilitarianism and (under regularity conditions) maximin are implemented; in those cases can $\rho(\mathbf{K})$ be interpreted as a utility discount rate.

In all our examples, we show that Assumptions 1 and 2 are satisfied for resource allocation mechanisms that are optimal in sense that they, for any initial stocks, 
implement paths that are weakly preferred to any feasible path according to the social preferences. We conjecture that Assumptions 1 and 2 are necessary for optimal resource allocation if the social preferences and the technological environment satisfy the following condition: There does not exist an alternative path that, compared to an optimal path, has higher utility in an initial period, at the end of which the alternative path is deemed as good as the optimal path. ${ }^{3}$ The investigation of such a primitive condition on preferences and technology seems, however, to require a discrete time framework and, thus, falls outside the scope of the present paper.

Based on our two assumptions we now obtain the following lemma.

Lemma 2 Under Assumptions 1 and $2, W^{*}(t)$ is continuous and

$$
\dot{W}^{*}(t)=\rho\left(\mathbf{K}^{*}(t)\right) \boldsymbol{\Psi}(\boldsymbol{t}) \mathbf{I}^{*}(t)
$$

holds at almost every $t$ at which $\mathbf{I}^{*}(t) \neq 0$.

Proof. $W^{*}(t)$ is continuous since $W$ and $\mathbf{K}^{*}(t)$ are continuous. Since $U$ is concave and $S(\mathbf{K})$ is convex and smooth, it follows that there is a unique $n$-dimensional hyperplane that supports the set of feasible $(n+1)$-dimensional utility-investment vectors. By comparing the maximum principle with Assumption 2, this implies that

$$
\nabla W\left(\mathbf{K}^{*}(t)\right)=\rho\left(\mathbf{K}^{*}(t)\right) \mathbf{\Psi}(t)
$$

holds at every $t$ at which $W\left(\mathbf{K}^{*}(t)\right)$ is differentiable. Hence, if $\left\{\mathbf{K}^{*}(t)\right\}$ does not spend a positive measure of time at points in $\mathbf{K}$-space at which $W$ is not differentiable, then we obtain that $\dot{W}^{*}=\nabla W\left(\mathbf{K}^{*}\right) \mathbf{I}^{*}=\rho\left(\mathbf{K}^{*}\right) \mathbf{\Psi} \mathbf{I}^{*}$ holds at almost every $t$. Otherwise, by assumption, $\left\{\mathbf{K}^{*}(t)\right\}$ has been absorbed at some capital vector $\mathbf{K}^{\infty}$, so that $\mathbf{I}^{*}(t)=0$ from then on.

\footnotetext{
${ }^{3}$ In the case of maximin, this condition holds if maximin paths are regular, while it can fail otherwise, e.g., in a one-sector model with the initial capital stock exceeding the golden rule level.

The maximin criterion illustrates that Assumption 2 does not necessarily mean that there is a linear trade-off between current utility and welfare improvement. Rather, it is sufficient that there is an $n$-dimensional hyperplane that separates the set of feasible $(n+1)$-dimensional utility-investment vectors from the set of vectors that are socially more preferable.

Assumptions 1 and 2 can hold even if the resource allocation mechanism does not implement an optimal path. E.g., suppose that society adheres to discounted utilitarianism in a technology where implementation of discounted utilitarianism would have lead to non-constant utility, but, in fact, a regular maximin path is implemented. Then, since the utility level that if held constant is equally as good as the implemented path is equal to the actual utility level, the welfare index is identical to the one arising if society had adhered to maximin and implemented an optimal path.
} 
Lemma 2 shows that the sign of the value of net investments along the implemented path indicates whether welfare is increasing, since the case not covered by the lemma, $\mathbf{I}^{*}(t)=0$, trivially implies $\dot{W}^{*}(t)=0$.

The main result of the present section follows from Lemmas 1 and 2.

Proposition 1 Under Assumptions 1 and 2, dynamic welfare is increasing if and only if there is growth in $U\left(\mathbf{C}^{*}(t)\right)+\mathbf{\Psi}(t) \mathbf{I}^{*}(t)$.

This result means that dynamic welfare is increasing if and only if utility NNP is increasing. Thus, changes in dynamic welfare according to the unspecified aggregation of the interests of different generations are revealed through changes in $U\left(\mathbf{C}^{*}(t)\right)+\boldsymbol{\Psi}(t) \mathbf{I}^{*}(t)$.

Lemmas 1 and 2 shed light on the problems associated with using utility NNP as a global welfare index, so that

$$
W\left(\mathbf{K}^{*}(t)\right)=U\left(\mathbf{C}^{*}(t)\right)+\mathbf{\Psi}(t) \mathbf{I}^{*}(t)
$$

holds at each $t$. Since

$$
\begin{gathered}
\dot{W}^{*}=\rho\left(\mathbf{K}^{*}\right) \mathbf{\Psi} \mathbf{I}^{*} \quad(\text { by Lemma } 2), \text { and } \\
d\left(U\left(\mathbf{C}^{*}\right)+\mathbf{\Psi} \mathbf{I}^{*}\right) / d t=-\frac{\dot{\mu}}{\mu} \boldsymbol{\Psi} \mathbf{I}^{*} \quad(\text { by Lemma } 1),
\end{gathered}
$$

the combination of $\rho\left(\mathbf{K}^{*}\right) \neq-\dot{\mu} / \mu$ and $\mathbf{\Psi} \mathbf{I}^{*} \neq 0$ implies that utility NNP cannot serve as a global representation of welfare. As shown in Sect. 3, it works for discounted utilitarianism because $\rho\left(\mathbf{K}^{*}\right)=-\frac{\dot{\mu}}{\mu}$, and it works for maximin because $\mathbf{\Psi} \mathbf{I}^{*}=0$. However, in general we must allow for cases where $\rho\left(\mathbf{K}^{*}\right) \neq-\dot{\mu} / \mu$ is combined with $\mathbf{\Psi} \mathbf{I}^{*} \neq 0$ and, thus, $W\left(\mathbf{K}^{*}\right)=U\left(\mathbf{C}^{*}\right)+\mathbf{\Psi} \mathbf{I}^{*}$ cannot hold at each $t$. Hence, it is not a general result that dynamic welfare can be represented by utility NNP. Rather, Prop. 1 shows that, along the implemented path, changes in utility NNP qualitatively measure changes in welfare.

In Sect. 6 we provide two additional examples of resource allocations mechanisms, by describing in the context of the Dasgupta-Heal-Solow model of capital accumulation and resource depletion (i) a society with a preference for progress and (ii) a society with a sustainability constraint. In the former case, welfare can not be represented by utility NNP; market prices can still measure welfare improvement locally in time. In the latter case, measurement of welfare improvement through market prices is useful for asset management. First, however, we show how to translate Prop. 1 into the positive result that growth in real NNP measured in market prices indicates local-in-time welfare improvement. 


\section{$5 \quad$ Real NNP growth and local comparisons}

Until now we have considered NNP and the value of net investments in utility terms. Utility, however, is not measurable directly, while market prices are. Comprehensive NNP that is measurable by market prices is frequently identified in the literature with the "linearized" Hamiltonian (cf. Hartwick, 1990), being the sum of the value of consumption and the value of net investments, measured in monetary units. Adapting Lemma 2 to this empirically more relevant aggregate implies that welfare is increasing if and only if measurable NNP exceeds the value of consumption.

This is, however a different kind of welfare significance than the one sought by Weitzman (1976), where higher welfare is indicated by greater NNP. The latter interpretation would translate here into a result that welfare is increasing along the time axis if and only if measurable NNP is also increasing. To demonstrate this, we show now that the analysis of Asheim and Weitzman (2001) can be adapted to the present more general setting. We are - like Asheim and Weitzman (2001) - only concerned with local-in-time comparisons along the implemented path.

When the path implemented by the resource allocation mechanism is realized through an intertemporal competitive equilibrium, market prices will be expressed in monetary units. Neither the vector of marginal utilities, $\nabla U\left(\mathbf{C}^{*}\right)$, nor the vector of investment prices in utility units, $\boldsymbol{\Psi}$, are directly observable. Rather, what may be observed directly are nominal prices at time $t$ for consumption goods and investment flows, given respectively by

$$
\begin{gathered}
\mathbf{p}(t)=\nabla U\left(\mathbf{C}^{*}(t)\right) / \lambda(t) \\
\mathbf{q}(t)=\mathbf{\Psi}(t) / \lambda(t),
\end{gathered}
$$

and a nominal interest rate at time $t, r(t)$, given by

$$
r(t)=-\frac{\dot{\mu}(t)}{\mu(t)}-\frac{\dot{\lambda}(t)}{\lambda(t)}
$$

where $\lambda(t)>0$ is the not-directly-observable marginal utility of current expenditures, which may depend on the "quantity of money" at time $t$. Assume that $\lambda(t)$ is continuous.

Define comprehensive NNP in nominal prices, $y(t)$, as the sum of the nominal value of consumption and the nominal value of net investments:

$$
y(t):=\mathbf{p}(t) \mathbf{C}^{*}(t)+\mathbf{q}(t) \mathbf{I}^{*}(t) .
$$


Under Assumption 1 it follows from the convexity of $S$ and the maximum principle that the consumption-investment pair maximizes the value of current production at each $t$ along the implemented path:

$$
y(t)=\max _{(\mathbf{C}, \mathbf{I}) \in S\left(\mathbf{K}^{*}(t)\right)} \mathbf{p}(t) \mathbf{C}+\mathbf{q}(t) \mathbf{I} .
$$

Furthermore, if $\{(\mathbf{C}, \mathbf{I}, \mathbf{K}) \mid(\mathbf{C}, \mathbf{I}) \in S(\mathbf{K})\}$ is a convex set, then Assumption 1 implies that the implemented path corresponds to an intertemporal competitive equilibrium since, to the given prices, consumers maximize utility and producers maximize profit:

$$
\begin{gathered}
\mathbf{C}^{*}(t) \text { maximizes } U(\mathbf{C})-\lambda(t) \mathbf{p}(t) \mathbf{C}, \\
\left(\mathbf{C}^{*}(t), \mathbf{I}^{*}(t), \mathbf{K}^{*}(t)\right) \text { maximizes } \mathbf{p}(t) \mathbf{C}+\mathbf{q}(t) \mathbf{I}-(r(t) \mathbf{q}(t)-\dot{\mathbf{q}}(t)) \mathbf{K} \\
\text { over all }(\mathbf{C}, \mathbf{I}, \mathbf{K}) \text { satisfying }(\mathbf{C}, \mathbf{I}) \in S(\mathbf{K}),
\end{gathered}
$$

where $r(t) q_{j}(t)-\dot{q}_{j}(t)$ is the nominal cost of holding one unit of capital good $j$. Here, (7) follows from the concavity of $U$, while (8) uses the property that $\nabla_{\mathbf{K}} H=$ $(-\dot{\mu} / \mu) \mathbf{\Psi}-\dot{\boldsymbol{\Psi}}=(-\dot{\mu} / \mu) \lambda \mathbf{q}-\dot{\lambda} \mathbf{q}-\lambda \dot{\mathbf{q}}=\lambda(r \mathbf{q}-\dot{\mathbf{q}})$. This latter property also means that Lemma 1, expressed in nominal prices, yields

$$
\mathbf{p}(t) \dot{\mathbf{C}}^{*}(t)+d\left(\mathbf{q}(t) \mathbf{I}^{*}(t)\right) / d t=r(t) \mathbf{q}(t) \mathbf{I}^{*}(t) .
$$

It follows from Lemma 2 that dynamic welfare is increasing if and only if NNP in nominal prices exceeds the value of consumption:

$$
\dot{W}^{*}(t)>0 \Leftrightarrow y(t)-\mathbf{p}(t) \mathbf{C}^{*}(t)=\mathbf{q}(t) \mathbf{I}^{*}(t)>0 .
$$

However, since the level of NNP in nominal prices at $t$ depends on $\lambda(t)$, and $\lambda(t)$ is arbitrary, the condition that $\dot{y}(t)>0$ need not signify welfare improvement. For a change in NNP (as opposed to a comparison of NNP with the value of consumption) to indicate a change in welfare, NNP must be measured in real prices. How then should NNP in real prices be determined?

To show how real NNP growth indicates welfare improvement, Asheim and Weitzman (2001) build upon a finding by Sefton and Weale (2000), namely that a Divisia consumption price index is of essential importance when expressing comprehensive NNP in real prices. The application of a price index $\{\pi(t)\}$ turns nominal prices $\{\mathbf{p}(t), \mathbf{q}(t)\}$ into real prices $\{\mathbf{P}(t), \mathbf{Q}(t)\}$,

$$
\begin{aligned}
\mathbf{P}(t) & =\mathbf{p}(t) / \pi(t) \\
\mathbf{Q}(t) & =\mathbf{q}(t) / \pi(t),
\end{aligned}
$$


implying that the real interest rate, $R(t)$, at time $t$ is given by

$$
R(t)=r(t)-\frac{\dot{\pi}(t)}{\pi(t)} .
$$

A Divisia consumption price index satisfies

$$
\frac{\dot{\pi}(t)}{\pi(t)}=\frac{\dot{\mathbf{p}}(t) \mathbf{C}^{*}(t)}{\mathbf{p}(t) \mathbf{C}^{*}(t)}
$$

implying that $\pi(t)$ is continuous and $\dot{\mathbf{P}} \mathbf{C}^{*}=0$ holds at almost every $t$ :

$$
\dot{\mathbf{P}} \mathbf{C}^{*}=\frac{d}{d t}\left(\frac{\mathbf{p}}{\pi}\right) \mathbf{C}^{*}=\frac{\pi \dot{\mathbf{p}} \mathbf{C}^{*}-\dot{\pi} \mathbf{p} \mathbf{C}^{*}}{\pi^{2}}=0 .
$$

Define comprehensive NNP in real Divisia prices, $Y(t)$, as the sum of the real value of consumption and the real value of net investments:

$$
Y(t):=\mathbf{P}(t) \mathbf{C}^{*}(t)+\mathbf{Q}(t) \mathbf{I}^{*}(t) .
$$

Lemma 3 Under Assumption 1, $Y(t)$ is continuous and

$$
\dot{Y}(t)=R(t)\left(Y(t)-\mathbf{P}(t) \mathbf{C}^{*}(t)\right)
$$

holds at almost every $t$.

Proof. That $Y$ is continuous follows from the continuity of $U\left(\mathbf{C}^{*}\right)+\mathbf{\Psi} \mathbf{I}^{*}$ (cf. Lemma 1) since $U$ has continuous partial derivatives and both $\lambda$ and $\pi$ are continuous. Furthermore, it follows from the definition of $Y$ that

$$
\dot{Y}=d\left(\mathbf{P C}^{*}+\mathbf{Q I}^{*}\right) / d t=\mathbf{P} \dot{C}^{*}+d\left(\mathbf{Q I}^{*}\right) / d t=R \mathbf{Q} \mathbf{I}^{*}=R\left(Y-\mathbf{P C}^{*}\right),
$$

where the second equality follows since $\dot{\mathbf{P}} \mathbf{C}^{*}=0$, and the third equality is obtained since (9) holds also for $\{\mathbf{P}(t), \mathbf{Q}(t)\}$ and $\{R(t)\}$.

Lemma 3 entails that

$$
\text { change in real } \mathrm{NNP}=\text { real interest rate } \cdot \text { value of net investments. }
$$

Since, by Lemma 2, a positive value of net investments indicates welfare improvement, we obtain the main result of Asheim and Weitzman (2001) in the current generalized setting.

Proposition 2 Provided that Assumptions 1 and 2 are satisfied and the real interest rate is positive, dynamic welfare is increasing if and only if there is growth in measurable NNP in real Divisia prices. 
Proof. The result follow from Lemmas 2 and 3 since

$$
\rho\left(\mathbf{K}^{*}\right) \mathbf{\Psi} \mathbf{I}^{*}=\rho\left(\mathbf{K}^{*}\right) \lambda \pi \mathbf{Q} \mathbf{I}^{*}=\rho\left(\mathbf{K}^{*}\right) \lambda \pi \mathbf{Q}\left(Y-\mathbf{P C}^{*}\right)
$$

with $\rho\left(\mathbf{K}^{*}\right), \lambda$, and $\pi$ all positive, if $\mathbf{I}^{*} \neq 0$, and $\dot{W}^{*}=0=\dot{Y}$ otherwise.

As noted by Asheim and Weitzman (2001), real NNP growth indicates welfare improvements locally in time. Unless real NNP grows in a monotone manner between $t^{\prime}$ and $t^{\prime \prime}$, it does not necessarily follow that a higher real NNP at $t^{\prime \prime}$ than $t^{\prime}$ indicates that welfare is higher at $t^{\prime \prime}$ compared to $t^{\prime}$.

\section{Progress and sustainability in a resource model}

We finally use the Dasgupta-Heal-Solow (DHS) model (cf. Dasgupta and Heal, 1974, 1979; Solow, 1974) of capital accumulation and resource depletion to illustrate the applicability of our framework.

In Sect. 6.1 we start with an exogenous investment rule that, when combined with efficiency (Assumption 1), leads to progress. We then apply our revealed welfare analysis (by invoking Assumption 2) and show how real NNP growth picks up that consumption increases in a sustainable manner. We confirm this welfare result by establishing that the investment rule is optimal under undiscounted utilitarianism. We note that - even though growth in measurable real NNP measures welfare improvement locally in time - utility NNP cannot be a global welfare indicator.

In Sect. 6.2 we consider a society maximizing the sum of discounted utilities within the subset of sustainable paths. We confirm that Assumptions 1 and 2 are satisfied and show how measurement of welfare improvement through real NNP growth can be useful for the management of society's assets: Real NNP growth approaching zero indicates that unconstrained development is no longer sustainable.

In the DHS model, a stock of man-made capital $\left(K_{M}\right)$ is combined with extracted raw material from a stock of a natural resource $\left(K_{N}\right)$ to produce output that can be split between consumption and investment. For tractability, we assume that the production function is Cobb-Douglas and exhibits CRS, implying that the consumption-investment pair $\left(C, I_{M}, I_{N}\right)$ is attainable given $\left(K_{M}, K_{N}\right)$ if and only if

$$
\begin{gathered}
C+I_{M} \leq K_{M}^{a} \cdot\left(-I_{N}\right)^{b}, \quad b<a<a+b=1 ; \\
C \geq 0, I_{N} \leq 0, K_{M} \geq 0, K_{N} \geq 0 .
\end{gathered}
$$


The assumption that $b<a$ is required to ensure that progress and sustainability are feasible in the present setting.

Consider paths for which $C,-I_{N}, K_{M}$, and $K_{N}$ remain positive throughout so that smoothness of the attainable set is satisfied. Let the ratio between man-made capital and output be denoted by $\kappa$ :

$$
\kappa=\frac{K_{M}}{K_{M}^{a} \cdot\left(-I_{N}\right)^{b}}=\left(\frac{K_{M}}{-I_{N}}\right)^{b} .
$$

If the implemented path satisfies Assumption 1, then the real interest rate along the path measures the marginal productivity of $K_{M}$ and is given by

$$
R(t)=\frac{a}{\kappa^{*}(t)},
$$

where $\kappa^{*}(t)$ is the capital-output ratio along the implemented path at time $t$. Moreover, the real investment prices are given by

$$
\begin{aligned}
& Q_{M}(t)=1 \\
& Q_{N}(t)=b \cdot \kappa^{*}(t)^{\frac{a}{b}},
\end{aligned}
$$

since, with output as numeraire, $Q_{N}(t)$ measures the marginal productivity of $-I_{N}$. The Hotelling rule for short-run efficiency yields $\dot{Q}_{N}(t) / Q_{N}(t)=R(t)$, implying

$$
\dot{\kappa}^{*}(t)=b .
$$

If, an addition, the following transversality conditions are satisfied,

$$
\begin{aligned}
\lim _{t \rightarrow \infty} \frac{K_{M}^{*}(t)}{b \cdot \kappa^{*}(t)^{\frac{a}{b}}} & =0 \\
\lim _{t \rightarrow \infty} K_{N}^{*}(t) & =0,
\end{aligned}
$$

then routine calculations show that, by setting $U(C)=C$, Assumption 1 is satisfied: The implemented path maximizes $\int_{0}^{\infty}\left(1 /\left(b \cdot \kappa^{*}(t)^{\frac{a}{b}}\right)\right) \cdot C(t) d t$ over all feasible paths, for any initial stocks $\left(K_{M}^{0}, K_{N}^{0}\right) \gg 0$.

\subsection{Progress paths}

Consider first a resource allocation mechanism determined by efficiency conditions (12)-(14) and by the property that investment in man-made capital equals a fraction $\beta$ of total output:

$$
I_{M}=\beta K_{M}^{a}\left(-I_{N}\right)^{b} .
$$


Note that $b K_{M}^{a}\left(-I_{N}\right)^{b}$ equals resource rents; i.e., the share of output that is attributable to extraction of raw material. We know from Hartwick's rule (cf. Hartwick, 1977; Dixit et al., 1980) that reinvesting resource rents forever leads to constant consumption. We assume $b<\beta<a ; \beta>b$ means that more than resource rents are reinvested by following (15), implying that such an investment policy leads to progress in the sense that consumption increases in a sustained manner, while $\beta<a$ is needed to ensure feasibility of the implemented path. We show next how the general approach developed in Sect. 4 and 5 can be applied to such "progress paths".

The resource allocation mechanism determines consumption, accumulation of man-made capital, and extraction of the natural resource stock as functions of the pair of capital stocks $\left(K_{M}, K_{N}\right)$ that society has at its disposal. It follows from the definition of $\kappa$ and the investment rule (15) that these functions can, for any $\left(K_{M}, K_{N}\right) \gg 0$, be described by

$$
\begin{aligned}
C\left(K_{M}, K_{N}\right) & =(1-\beta) \cdot \frac{K_{M}}{\kappa\left(\frac{K_{M}}{K_{N}}\right)} \\
I_{M}\left(K_{M}, K_{N}\right) & =\beta \cdot \frac{K_{M}}{\kappa\left(\frac{K_{M}}{K_{N}}\right)} \\
I_{N}\left(K_{M}, K_{N}\right) & =-\frac{K_{M}}{\kappa\left(\frac{K_{M}}{K_{N}}\right)^{\frac{1}{b}}},
\end{aligned}
$$

where, by imposing the efficiency conditions (12) and (14), we can calculate the capital-output ratio as an explicit function of $K_{M} / K_{N}$,

$$
\kappa\left(\frac{K_{M}}{K_{N}}\right)=(a-\beta)^{-\frac{b}{a}}\left(\frac{K_{M}}{K_{N}}\right)^{\frac{b}{a}},
$$

and check that $(13)$ is satisfied. For given initial stocks $\left(K_{M}^{0}, K_{N}^{0}\right)$ at time 0 , equations (17)-(19) determine the implemented path of capital stocks, $\left\{K_{M}^{*}(t), K_{N}^{*}(t)\right\}$, which in turn yields the implemented paths of consumption and investment flows: $C^{*}(t)=C\left(K_{M}^{*}(t), K_{N}^{*}(t)\right), I_{M}^{*}(t)=I_{M}\left(K_{M}^{*}(t), K_{N}^{*}(t)\right)$, and $I_{N}^{*}(t)=I_{N}\left(K_{M}^{*}(t)\right.$, $\left.K_{N}^{*}(t)\right)$. By combining (16) and (17) with (12), we can establish that consumption grows at a positive (but decreasing) rate since $\beta>b$ :

$$
\frac{\dot{C}^{*}(t)}{C^{*}(t)}=\frac{\beta-b}{\kappa^{*}(t)}>0
$$

Moreover, by combining (10) and (11) with (19), it follows that the relative price of natural capital in terms of man-made capital is positively related to $\beta$, the parameter 
that indicates society's emphasis on progress:

$$
\frac{Q_{N}(t)}{Q_{M}(t)}=\frac{b}{a-\beta} \cdot \frac{K_{M}^{*}(t)}{K_{N}^{*}(t)} .
$$

By assuming that the implemented path does not waste opportunity for welfare improvement - i.e., by adding Assumption 2 - it follows from Prop. 2 that welfare is increasing if and only if there is real NNP growth, where real NNP can be written as

$$
C^{*}(t)+Q_{M}(t) I_{M}^{*}(t)+Q_{N}(t) I_{N}^{*}(t)=a \cdot \frac{K_{M}^{*}(t)}{\kappa^{*}(t)}
$$

due to the constant factor shares. It follows from (12) and (17) that the growth rate of NNP equals that of consumption. Thus, the revealed welfare analysis picks up that consumption increases in a sustained manner.

By Lemma 3 increased welfare can also be indicated by a positive value of net investments: $Q_{M}(t) I_{M}^{*}(t)+Q_{N}(t) I_{N}^{*}(t)>0$. Since (17)-(19) imply

$$
\frac{I_{N}\left(K_{M}, K_{N}\right)}{I_{M}\left(K_{M}, K_{N}\right)}=-\frac{a-\beta}{\beta} \cdot \frac{K_{N}}{K_{M}},
$$

we get from (20) that welfare is improving along the implemented path:

$$
Q_{M}(t) I_{M}^{*}(t)+Q_{N}(t) I_{N}^{*}(t)=I_{M}^{*}(t)\left(1-\frac{b}{\beta}\right)>0
$$

since $\beta>b$.

As shown in the proof of Lemma 2, Assumption 2 entails that any welfare index $W\left(K_{M}, K_{N}\right)$ satisfies

$$
\frac{\frac{\partial W\left(K_{M}, K_{N}\right)}{\partial K_{N}}}{\frac{\partial W\left(K_{M}, K_{N}\right)}{\partial K_{M}}}=\frac{\Psi_{N}}{\Psi_{M}}=\frac{Q_{N}}{Q_{M}}=\frac{b}{a-\beta} \cdot \frac{K_{M}}{K_{N}} .
$$

It is a direct consequence of (22) that welfare can be represented by

$$
W\left(K_{M}, K_{N}\right)=K_{M}^{a-\beta} K_{N}^{b}
$$

Moreover, it follows from (21) that the implemented path in $\left(K_{M}, K_{N}\right)$-space is described by

$$
K_{M}^{a-\beta} K_{N}^{\beta}=\text { constant }
$$

with $\dot{K}_{M}=I_{M}>0$ and $\dot{K}_{N}=I_{N}<0$. That welfare is improving along the implemented path can now alternatively be seen by comparing the iso-welfare contours 
given by $(23)$ with the contour that describes the implemented path in $\left(K_{M}, K_{N}\right)-$ space.

This discussion raises the following question: Are there social preferences such this resource allocation mechanism for any vector of initial stocks implements a most preferred path? This is answered by observing that the resource allocation mechanism can be derived from the utilitarian problem of maximizing, without discounting,

$$
\int_{0}^{\infty}-C(t)^{-\frac{1-\beta}{\beta-b}} d t
$$

over all feasible paths. It follows from the analysis of Dasgupta and Heal (1979, pp. 303-308) that an undiscounted utilitarian optimum exists if

$$
\frac{1-\beta}{\beta-b}>\frac{1-a}{a-b}
$$

which implies $b<\beta<a$. This, of course, is the assumption we have imposed.

By considering the maximum value of the integral in (24) with $\left(K_{M}, K_{N}\right) \gg 0$ as initial stocks, we find that welfare can be represented by (23). This confirms the result that we have already derived through our revealed welfare analysis, namely that welfare is increasing along the implemented path.

Under discounted utilitarianism utility NNP is a global representation of dynamic welfare. This follows from equation (2) in Sect. 3, which is Weitzman's (1976) main result. Moreover, under maximin, the converse of Hartwick's rule implies that utility NNP is equal to the constant utility level and therefore a global welfare index. For the progress paths that we analyze here in the context of the DHS model, however, such a result is not obtained. Rather, it turns out that utility NNP cannot be a global welfare index.

Proposition 3 Consider the resource allocation determined by (16)-(18) in the context of the DHS model. There exists no utility function such that net national product in terms of utility is a global representation of welfare.

Proof. It follows from (15) and the constant factor shares that $Q_{M}(t) I_{M}^{*}(t)+$ $Q_{N}(t) I_{N}^{*}(t)=(\beta-b) C^{*}(t) /(1-\beta)$. Since $\Psi_{M}(t)=U^{\prime}\left(C^{*}(t)\right) \cdot Q_{M}(t)$ and $\Psi_{N}(t)=$ $U^{\prime}\left(C^{*}(t)\right) \cdot Q_{N}(t)$, this implies

$$
\text { Utility NNP }=U\left(C\left(K_{M}, K_{N}\right)\right)+U^{\prime}\left(C\left(K_{M}, K_{N}\right)\right) \frac{\beta-b}{1-\beta} C\left(K_{M}, K_{N}\right)
$$


for an arbitrary $U$ function, when the pair of capital stocks is $\left(K_{M}, K_{N}\right)$. Assume that utility NNP is a global welfare index. Then utility NNP must be invariant when moving along any iso-welfare contour defined by (23):

$$
\left(U^{\prime}(C)+U^{\prime}(C) \frac{\beta-b}{1-\beta}+U^{\prime \prime}(C) \frac{\beta-b}{1-\beta} C\right)\left(\frac{\partial C}{\partial K_{M}} d K_{M}+\frac{\partial C}{\partial K_{N}} d K_{N}\right)=0 .
$$

Since $C\left(K_{M}, K_{N}\right)$ increases when moving along an iso-welfare contour by increasing $K_{M}$ and decreasing $K_{N}$, the second parenthesis is non-zero and

$$
U^{\prime}(C) \frac{a}{\beta-b}+U^{\prime \prime}(C) C=0
$$

must hold. This implies that $U$ is in the class of affine transformations of

$$
U(C)=-C^{-\frac{1-\beta}{\beta-b}} .
$$

Since the implemented path maximizes (24), the supporting utility discount rate is zero throughout for any utility function in this class. Under these circumstances, Lemma 1 - extrapolated to the case with a zero utility discount rate -implies that utility NNP does not change as a consequence of non-zero value of net investments. Indeed, it follows that utility NNP is zero for any pair of initial stocks if the utility function is given by (25). Hence, utility NNP has no welfare significance within the class of utility functions that are affine transformations of (25).

Assumption 1 is not satisfied for any utility function in the class considered in the proof of Prop. 3, i.e. that is an affine transformation of (25). If we instead use a utility function so that Assumption 1 is satisfied for a path of supporting utility discount factors $\{\mu(t)\}$ with discount rates $-\dot{\mu}(t) / \mu(t)$ that are positive $(U(C)=C$ is an example), then

$$
\text { Utility NNP }=\int_{0}^{\infty}-\frac{\dot{\mu}(t)}{\mu(t)} \frac{\mu(t)}{\mu(0)} U\left(C^{*}(t)\right) d t
$$

see Sefton and Weale (1996). This implies that utility NNP is a weighted average of future utility. However, by following a given iso-welfare contour defined by (23) as $K_{M} \rightarrow \infty$ and $K_{N} \rightarrow 0$, and considering the consumption paths that would be implemented for these initial conditions, it can be shown that the minimal consumption (which occurs at time 0) along these paths goes to infinity. This means that the constant welfare along such an iso-welfare contour cannot be expressed as a weighted average of future utility. 
However, even though utility NNP cannot serve as a global representation of dynamic welfare, it is a consequence of the analysis of this paper (cf. Prop. 2) that growth in measurable NNP in real prices measures welfare improvement locally in time, even in the current setting. This illustrates the generality of the positive result that we report in Prop. 2.

\subsection{Sustainability as a constraint}

Consider now a society that deems unsustainable development unacceptable, and which adopts a resource allocation mechanism that among the acceptable sustainable paths implements the path that maximizes the sum of discounted utilities

$$
\int_{0}^{\infty} e^{-\rho t} U(C(t)) d t
$$

where $\rho$ is a positive and constant utility discount rate. ${ }^{4}$ We will demonstrate within this setting that Assumptions 1 and 2 are satisfied, so that our revealed welfare analysis applies. We will also show how information on the growth rate of real NNP (or equivalently, the value of net investments) can be useful for asset management by indicating when unconstrained development is no longer sustainable.

A consumption path is said to be sustainable if, at any time, current consumption does not exceed the maximum sustainable consumption level given the current capital stocks. Since unconstrained maximization of the sum of discounted utilities in the DHS model leads to consumption converging to zero as time goes to infinity, the sustainability constraint imposed on the implemented path is binding. Since by (12) the real interest rate $R(t)=a / \kappa^{*}(t)$ is decreasing along any efficient path, the sustainability constraint binds in an eventual phase with constant consumption, which can possibly be preceded by an unconstrained utilitarian phase with increasing consumption. For given initial stocks $\left(K_{M}^{0}, K_{N}^{0}\right) \gg 0$, the implemented path $\left\{C^{*}(t), I_{M}^{*}(t), I_{N}^{*}(t), K_{M}^{*}(t), K_{N}^{*}(t)\right\}$ can be determined by maximizing (26) subject to the constraint that consumption is non-decreasing; it follows from standard arguments that such a path exists.

Therefore, if, in this example, social preferences over paths are represented by (26) on the set of non-decreasing consumption paths, while paths that are not nondecreasing are strictly less preferred, then it follows that the resource allocation

\footnotetext{
${ }^{4}$ Asheim et al. (2001) present ethical axioms under which only sustainable paths are acceptable in the DHS model. Discounted utilitarian paths under a sustainability constraint in the DHS model are analyzed in continuous time by Asheim (1986) and Pezzey (1994).
} 
mechanism implements a most preferred path also in this case. Since implemented paths are non-decreasing, welfare $W\left(K_{M}^{0}, K_{N}^{0}\right)$ can be associated with the utility level that if held constant is equally as good when evaluated by (26):

$$
W\left(K_{M}^{0}, K_{N}^{0}\right)=\frac{\int_{0}^{\infty} e^{-\rho t} U\left(C^{*}(t)\right) d t}{\int_{0}^{\infty} e^{-\rho t} d t}=\rho \int_{0}^{\infty} e^{-\rho t} U\left(C^{*}(t)\right) d t
$$

To facilitate description of the resource allocation mechanism, assume that $U$ has constant elasticity of marginal utility; i.e., for all $C>0,-\left(U^{\prime \prime}(C) \cdot C\right) / U^{\prime}(C)=\eta>$ 0 . Then the resource allocation mechanism becomes homogenous of degree 1 since the production function exhibits CRS. In particular, the capital-output ratio $\kappa$ is a function of $K_{M} / K_{N}$, and the dividing line between the sustainability unconstrained and constrained regimes is a ray in $\left(K_{M}, K_{N}\right)$-space. Consumption is increasing if and only if the rate of return on an investment of current output yielding $a$ constant and perpetual increase in future consumption is greater than $\rho$. This rate of return is the infinitely long-term real interest rate, being the inverse of the value of a perpetual bond. It equals the discounted average of the (instantaneous) real interest rate, $a / \kappa^{*}(s)$, from time $t$ on:

$$
\frac{\int_{t}^{\infty}\left(1 /\left(b \cdot \kappa^{*}(s)^{\frac{a}{b}}\right)\right) \cdot\left(a / \kappa^{*}(s)\right) d s}{\int_{t}^{\infty} 1 /\left(b \cdot \kappa^{*}(s)^{\frac{a}{b}}\right) d s}=\frac{a-b}{\kappa^{*}(t)} .
$$

Note that the infinitely long-term interest rate $(a-b) / \kappa^{*}(t)$ is smaller than the instantaneous rate $a / \kappa^{*}(t)$ since the latter is decreasing throughout.

In the eventual sustainability constrained phase, the resource allocation mechanism implements efficient paths with constant consumption. Hence, in this phase the resource allocation mechanism is described by (16)-(19) with $\beta=b$. Since this phase is entered when the the infinitely long-term interest rate $(a-b) / \kappa^{*}(t)$ equals $\rho$, it follows from (19) that paths are in the unconstrained discounted utilitarian phase as long as

$$
\frac{K_{M}}{K_{N}}<\rho\left(\frac{a-b}{\rho}\right)^{\frac{1}{b}},
$$

and in the eventual sustainability constrained phase when

$$
\frac{K_{M}}{K_{N}} \geq \rho\left(\frac{a-b}{\rho}\right)^{\frac{1}{b}} .
$$

Assume for tractability that $U(C)=C^{b}$ so that $\eta=a$. Then the unconstrained discounted utilitarian phase is characterized by (16)-(18) with

$$
\beta=\beta(\kappa)=1-a \frac{\rho \kappa}{a^{2}-b^{2} \cdot e^{\frac{\rho \kappa-(a-b)}{a b}},}
$$


where it follows from (12) that

$$
\kappa:\left(0, \rho\left(\frac{a-b}{\rho}\right)^{\frac{1}{b}}\right) \rightarrow\left(0, \frac{a-b}{\rho}\right)
$$

is an increasing function of $K_{M} / K_{N}$ since $\dot{K}_{M}=I_{M}>0$ and $\dot{K}_{N}=I_{N}<0$ and continuous at $K_{M} / K_{N}=\rho((a-b) / \rho)^{1 / b}$ since $\kappa^{*}(t)$ is differentiable w.r.t. time. Note that $\beta$ is a decreasing function of $\kappa$ (and by (12) of time) and converges to $b$ as $\kappa$ approaches the value $(a-b) / \rho$ at which time paths enter into the sustainability constrained phase. Hence, output, $C, I_{M}$, and $I_{N}$ are throughout continuous functions of $\left(K_{M}, K_{N}\right)$ and, thus, of time.

Fix the initial stocks $\left(K_{M}^{0}, K_{N}^{0}\right) \gg 0$ and consider the implemented path determined by the resource allocation mechanism described above. Let $\tau$ denote the time at which the implemented path enters the eventual sustainability constrained phase. Set $\tau=0$ if the path starts in this phase, i.e., if $K_{M}^{0} / K_{N}^{0} \geq \rho((a-b) / \rho)^{1 / b}$. We now verify that this path does indeed satisfy Assumptions 1 and 2 and maximize (26) subject to consumption being non-decreasing.

Assumption 1 is satisfied for the continuous path of supporting utility discount factors $\{\mu(t)\}$ determined (up to the choice of numeraire) by

$$
\begin{gathered}
\frac{\mu(t)}{\int_{t}^{\infty} \mu(s) d s}=\rho \text { for } t \in[0, \tau) \\
\frac{\mu(t)}{\int_{t}^{\infty} \mu(s) d s}=\frac{a-b}{\kappa^{*}(t)} \text { for } t \in[\tau, \infty),
\end{gathered}
$$

implying that utility discount rates are positive: $-\dot{\mu}(t) / \mu(t)=\rho$ for $t \in(0, \tau)$ and $-\dot{\mu}(t) / \mu(t)=a / \kappa^{*}(t)$ for $t \in(\tau, \infty)$. This can be seen by choosing a path of investment prices in terms of utility $\left\{\Psi_{M}(t), \Psi_{N}(t)\right\}$ so that the current-value Hamiltonian is maximized at any point in time:

$$
\begin{aligned}
& \Psi_{M}(t)=U^{\prime}\left(C^{*}(t)\right) \cdot Q_{M}(t)=b C^{*}(t)^{-a} \\
& \Psi_{N}(t)=U^{\prime}\left(C^{*}(t)\right) \cdot Q_{N}(t)=b C^{*}(t)^{-a} \cdot b \kappa^{*}(t)^{\frac{a}{b}} .
\end{aligned}
$$

Then the co-state differential equations hold,

$$
\begin{aligned}
\frac{a}{\kappa^{*}(t)} \Psi_{M}(t) & =-\frac{\dot{\mu}(t)}{\mu(t)} \Psi_{M}(t)-\dot{\Psi}_{M}(t) \\
0 & =-\frac{\dot{\mu}(t)}{\mu(t)} \Psi_{N}(t)-\dot{\Psi}_{N}(t),
\end{aligned}
$$

and the consumption path satisfies Ramsey's rule:

$$
\frac{a}{\kappa^{*}(t)}=-\frac{\dot{\mu}(t)}{\mu(t)}+a \frac{\dot{C}^{*}(t)}{C^{*}(t)}
$$


Since $-\dot{\mu}(t) / \mu(t)$ jumps from $\rho=(a-b) / \kappa^{*}(\tau)$ to $a / \kappa^{*}(\tau)$ when the sustainability constrained phase is entered, it follows from (28) that the rate of consumption growth decreases abruptly from $b /\left(a \kappa^{*}(\tau)\right)$ to 0 at that time.

The following result, which is proven in the appendix, establishes formally that (26) is maximized subject to consumption being non-decreasing.

Lemma 4 For any initial stocks $\left(K_{M}^{0}, K_{N}^{0}\right) \gg 0$, the path implemented by the resource allocation mechanism described above maximizes $\int_{0}^{\infty} e^{-\rho t} C(t)^{b} d t$ over all feasible non-decreasing consumption paths.

To apply the revealed welfare analysis of Sects. 4 and 5, we must show that Assumption 2 is satisfied. It follows from (27) that

$$
\begin{aligned}
& \frac{\mu(t)}{\int_{0}^{\infty} \mu(s) d s}=\rho e^{-\rho t} \text { for } t \in[0, \tau) \\
& \frac{\int_{\tau}^{\infty} \mu(s) d s}{\int_{0}^{\infty} \mu(s) d s}=\rho \int_{\tau}^{\infty} e^{-\rho s} d s .
\end{aligned}
$$

Hence, since consumption is constant in the eventual sustainability constrained phase, we have that $W\left(K_{M}^{0}, K_{N}^{0}\right)$ can be rewritten as follows:

$$
W\left(K_{M}^{0}, K_{N}^{0}\right)=\rho \int_{0}^{\infty} e^{-\rho t} C^{*}(t)^{b} d t=\frac{\int_{0}^{\infty} \mu(t) C^{*}(t)^{b} d t}{\int_{0}^{\infty} \mu(t) d t} .
$$

Since $\left(\Psi_{M}(0), \Psi_{N}(0)\right)$ is the vector of partial derivatives of $\int_{0}^{\infty} \mu(t) C^{*}(t)^{b} d t$ w.r.t. the initial stocks, we obtain by invoking the envelope theorem that

$$
\frac{\partial W\left(K_{M}^{0}, K_{N}^{0}\right)}{\partial K_{M}}=\frac{\mu(0)}{\int_{0}^{\infty} \mu(t) d t} \Psi_{M}(0) \quad \text { and } \quad \frac{\partial W\left(K_{M}^{0}, K_{N}^{0}\right)}{\partial K_{N}}=\frac{\mu(0)}{\int_{0}^{\infty} \mu(t) d t} \Psi_{N}(0) .
$$

Hence, Assumption 2 is satisfied since, by setting

$$
\rho\left(K_{M}^{0}, K_{N}^{0}\right)=\frac{\mu(0)}{\int_{0}^{\infty} \mu(t) d t},
$$

the maximum principle implies that $\left(C^{*}(0), I_{M}^{*}(0), I_{N}^{*}(0)\right)$ maximizes

$$
\rho\left(K_{M}^{0}, K_{N}^{0}\right) C^{b}+\frac{\partial W\left(K_{M}^{0}, K_{N}^{0}\right)}{\partial K_{M}} I_{M}+\frac{\partial W\left(K_{M}^{0}, K_{N}^{0}\right)}{\partial K_{N}} I_{N}
$$

over all attainable consumption-investment pairs.

It now follows from Prop. 2 that welfare is increasing if and only if there is growth in real NNP, $a K_{M}^{*}(t) / \kappa^{*}(t)$. Since (12) implies that the growth rate of real NNP equals $(\beta(\kappa)-b) / \kappa$, welfare is increasing as long as the path remains in the unconstrained utilitarian phase, during which $\beta(\kappa)>b$. Since $\beta(\kappa)$ reaches $b$ at the point in time at 
which the sustainability constraint becomes binding, the observation that the growth rate of real NNP decreases towards zero indicates that unconstrained development is no longer sustainable. Hence, the information on welfare changes offered by the growth rate of real NNP is useful for the management of society's assets, given that unsustainable paths are deemed socially unacceptable. Note that consumption yields no such indication, since the rate of consumption growth falls discontinuously to zero at the time the path enters the sustainability constrained phase.

By Lemma 3 increased welfare can also be indicated by the value of net investments, $Q_{M}(t) I_{M}^{*}(t)+Q_{N}(t) I_{N}^{*}(t)=I_{M}^{*}(t)\left(1-b / \beta\left(\kappa^{*}(t)\right)\right)$, being positive. Again $\beta(\kappa)>b$ during the unconstrained utilitarian phase implies that welfare is increasing, while the observation that the value of net investments decreases towards zero as $\beta(\kappa)$ approaches $b$ indicates that unconstrained development is no longer sustainable. Thus, also the sign of the value of net investments is useful for asset management.

Note that the growth rate of NNP (and equivalently, the value of net investments) indicates when the sustainability constraint becomes binding precisely because policies implementing sustainable development are expected and, hence, reflected in the ratio of investment prices. It is well-known that sustainability cannot be indicated in this manner if instead an unconstrained utilitarian path is expected to be followed throughout (cf. Asheim, 1994; Pezzey, 1994).

\section{Concluding remarks}

We have established that growing real NNP - or equivalently, a positive value of net investments - can be used to indicate welfare improvement, independently of the welfare criterion adopted by society. As long as the policies that society implements leads to an efficient path that does not waste opportunity for welfare improvement, the underlying - but unspecified and unobservable - welfare judgements will be revealed through prices and quantities that are available in a perfect market economy. It is a merit of such a revealed welfare approach that we need not be concerned with what the actual social preferences are when drawing welfare conclusions on the basis of national accounting aggregates.

We have thus shown that the result of Asheim and Weitzman (2001) - namely that increasing measurable NNP in real Divisia prices indicates welfare improvement in a multiple consumption good setting even when utility itself is not measurablecan be generalized further to situations where society does not subscribe to dis- 
counted utilitarianism. Thus, the present analysis covers also circumstances where, for example, progress and sustainability are important concerns. We have exemplified this in Sect. 3 by showing in general that maximin, in addition to discounted utilitarianism, is encompassed by the present approach, and in Sect. 6 by considering two resource allocation mechanisms in the Dasgupta-Heal-Solow model of capital accumulation and resource depletion; one that implements undiscounted utilitarianism and one that maximizes the sum of discounted utilities within the subset of sustainable paths. In the latter case, real NNP growth approaching zero indicates that unconstrained development is no longer sustainable.

\section{References}

Asheim, G.B. (1986), Rawlsian intergenerational justice as a Markov-perfect equilibrium in a resource technology. Discussion Paper 6/1986, Norwegian School of Economics and Business Administration, Bergen (A version with descrete time analysis is published in the Review of Economic Studies 55 (1988), 469-484).

Asheim, G.B. (1994), Net National Product as an Indicator of Sustainability. Scandinavian Journal of Economics 96, 257-265.

Asheim, G.B., Buchholz, W., and Tungodden, B. (2001), Justifying sustainability. Journal of Environmental Economics and Managment 41, 252-268.

Asheim, G.B. and Weitzman, M.L. (2001), Does NNP growth indicate welfare improvement? Economics Letters 73, 233-239.

Burmeister, E. and Hammond, P. (1977), Maximin paths of heterogeneous capital accumulation and the instability of paradoxical steady states. Econometrica 45, 853-870.

Cairns, R.D. (2000), Sustainability accounting and green accounting. Environment and Development Economics 5, 49-54.

Dasgupta, P.S. (2001), Valuing objects and evaluating policies in imperfect economies. Economic Journal 111, C1-C29.

Dasgupta, P.S. and Heal, G.M. (1974), The optimal depletion of exhaustible resources. Review of Economic Studies (Symposium), 3-28.

Dasgupta, P.S. and Heal, G.M. (1979), Economic Theory and Exhaustible Resources. Cambridge University Press, Cambridge, UK.

Dasgupta, P.S. and Mäler, K.-G. (2000), Net national product, wealth, and social well-being. Environment and Development Economics 5, 69-93. 
Dixit, A., Hammond, P., and Hoel, M. (1980), On Hartwick's rule for regular maximin paths of capital accumulation and resource depletion. Review of Economic Studies 47, 551-556.

Hamilton, K. and Clemens, M. (1999), Genuine savings in developing countries. World Bank Economic Review 13, 333-356.

Hartwick, J. (1977), Intergenerational equity and investing rents from exhaustible resources. American Economic Review 66, 972-974.

Hartwick, J. (1990), National resources, national accounting, and economic depreciation. Journal of Public Economics 43, 291-304.

Hicks, J. (1946), Value and Capital. 2nd edition. Oxford University Press, Oxford.

Mas-Colell, A., Whinston, M.D., and Green, J.R. (1995), Microeconomic Theory. Oxford University Press, Oxford.

Pemberton, M. and Ulph, D. (2001), Measuring income and measuring sustainability. Scandinavian Journal of Economics 103, 25-40.

Pezzey, J. (1994), Theoretical Essays on Sustainability and Environmental Policy. Ph.D. thesis, University of Bristol.

Rawls, J. (1971), A Theory of Justice. Harvard University Press, Cambridge, MA.

Samuelson, P. (1961), The evaluation of 'Social income': Capital formation and wealth. In The Theory of Capital (eds. Lutz and Hague), pp. 32-57. St. Martin's Press, New York.

Sefton, J.A. and Weale, M.R (1996), The net national product and exhaustible resources: The effects of foreign trade. Journal of Public Economics 61, 21-47.

Sefton, J.A. and Weale, M.R. (2000), Real National Income. NIESR, London.

Solow, R.M. (1974), Intergenerational equity and exhaustible resources. Review of Economic Studies (Symposium), 29-45.

Varian, H.R (1992), Microeconomic Analysis. Norton, New York.

Weitzman, M.L. (1976), On the welfare significance of national product in a dynamic economy. Quarterly Journal of Economics 90, 156-162.

Withagen, C. and Asheim, G.B. (1998), Characterizing sustainability: The converse of Hartwick's rule. Journal of Economic Dynamics and Control 23, 159-165. 


\section{Appendix: Proof of Lemma 4}

For fixed $\left(K_{M}^{0}, K_{N}^{0}\right) \gg 0$, let $\left\{C^{*}(t)\right\}$ be the consumption path implemented by the resource allocation mechanism and let $\{C(t)\}$ denote any feasible non-decreasing consumption path. It is sufficient to show that

$$
\lim \sup _{T \rightarrow \infty} \int_{0}^{T} e^{-\rho t}\left(C(t)^{b}-C^{*}(t)^{b}\right) d t \leq 0 .
$$

Normalize $\{\mu(t)\}$ such that $\int_{0}^{\infty} \mu(t) d t=\int_{0}^{\infty} e^{-\rho t} d t=1 / \rho$. This implies that

$$
\mu(0)=1 \text { if } \frac{K_{M}^{0}}{K_{N}^{0}} \leq \rho\left(\frac{a-b}{\rho}\right)^{\frac{1}{b}} \quad \text { and } \quad 0<\mu(0)<1 \text { if } \frac{K_{M}^{0}}{K_{N}^{0}}>\rho\left(\frac{a-b}{\rho}\right)^{\frac{1}{b}} .
$$

By (27), there exists a time $\sigma>\tau$ such that

$$
\mu(t) \leq e^{-\rho t} \text { for } t \in[0, \sigma] \text { and } \mu(t)>e^{-\rho t} \text { for } t \in(\sigma, \infty) .
$$

Then, since $\int_{0}^{\infty} e^{-\rho t} d t=\int_{0}^{\infty} \mu(t) d t, e^{-\rho t}=\mu(t)$ for $t \in(0, \tau)$, and $C^{*}(t)=C^{*}(\sigma)$ for $t \in(\tau, \infty)$, it follows that

$$
\begin{aligned}
& \lim \sup _{T \rightarrow \infty} \int_{0}^{T} e^{-\rho t}\left(C(t)^{b}-C^{*}(t)^{b}\right) d t \\
= & \lim \sup _{T \rightarrow \infty} \int_{0}^{T}\left(e^{-\rho t} C(t)^{b}-\mu(t) C^{*}(t)^{b}\right) d t \\
= & \lim \sup _{T \rightarrow \infty} \int_{0}^{T}\left(e^{-\rho t}-\mu(t)\right) C(t)^{b} d t+\lim \sup _{T \rightarrow \infty} \int_{0}^{T} \mu(t)\left(C(t)^{b}-C^{*}(t)^{b}\right) d t \\
\leq & \lim \sup _{T \rightarrow \infty} \int_{0}^{T}\left(e^{-\rho t}-\mu(t)\right) C(t)^{b} d t \quad \text { since Assumption } 1 \text { is satisfied } \\
= & \lim \sup _{T \rightarrow \infty} \int_{0}^{T}\left(e^{-\rho t}-\mu(t)\right)\left(C(t)^{b}-C(\sigma)^{b}\right) d t \quad \text { since } \int_{0}^{\infty} e^{-\rho t} d t=\int_{0}^{\infty} \mu(t) d t
\end{aligned}
$$

$\leq 0$ by the definition of $\sigma$ since $\{C(t)\}$ is non-decreasing. 